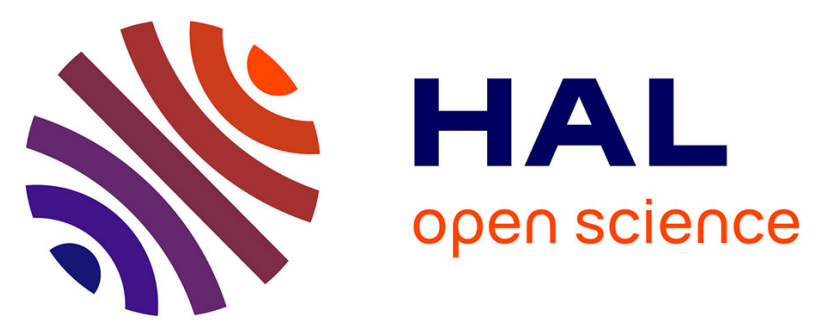

\title{
FASTING HYPERGLYCEMIA AND IN-HOSPITAL MORTALITY IN ELDERLY POPULATION
}

Pedro Iglesias, Antonio Polini, Angélica Muñoz, Angela Dardano, Florentino

Prado, Maido Castiglioni, María Teresa Guerrero, Sara Tognini, María Cruz Macías, Juan J Díez, et al.

\section{To cite this version:}

Pedro Iglesias, Antonio Polini, Angélica Muñoz, Angela Dardano, Florentino Prado, et al.. FASTING HYPERGLYCEMIA AND IN-HOSPITAL MORTALITY IN ELDERLY POPULATION. International Journal of Clinical Practice, 2011, 65 (3), pp.308. 10.1111/j.1742-1241.2010.02514.x . hal-00614655

\section{HAL Id: hal-00614655 \\ https://hal.science/hal-00614655}

Submitted on 14 Aug 2011

HAL is a multi-disciplinary open access archive for the deposit and dissemination of scientific research documents, whether they are published or not. The documents may come from teaching and research institutions in France or abroad, or from public or private research centers.
L'archive ouverte pluridisciplinaire HAL, est destinée au dépôt et à la diffusion de documents scientifiques de niveau recherche, publiés ou non, émanant des établissements d'enseignement et de recherche français ou étrangers, des laboratoires publics ou privés. 


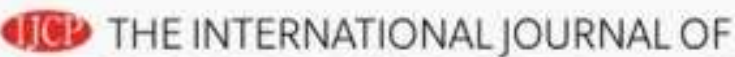 CLINICAL PRACTICE}

\section{FASTING HYPERGLYCEMIA AND IN-HOSPITAL MORTALITY IN ELDERLY POPULATION}

\begin{tabular}{|r|l|}
\hline Journal: & International Journal of Clinical Practice \\
\hline Manuscript ID: & IJCP-07-10-0361.R1 \\
\hline Datey - Manuscript type: & Original Paper \\
\hline Author: & 04-Aug-2010 \\
& $\begin{array}{l}\text { Complete List of Authors: } \\
\text { Muñoz, Angélica; Hospital General, Geriatrics } \\
\text { Prado, Florentino; Hospital General, Geriatrics } \\
\text { Castiglioni, Maido; University of Pisa, Internal Medicine } \\
\text { Guerrero, María Teresa; Hospital General, Geriatrics } \\
\text { Tognini, Sara; Cisanello Hospital, Internal Medicine } \\
\text { Macías, María Cruz; Hospital General, Geriatrics } \\
\text { Díez, Juan J; Hospital Ramón y Cajal, Endocrinology } \\
\text { Monzani, Fabio; University of Pisa, Internal Medicine }\end{array}$ \\
\hline Specialty area: & \multicolumn{2}{|c}{} \\
\hline \multicolumn{2}{|c|}{} \\
\hline
\end{tabular}

\section{SCHOLARONE ${ }^{m}$ Manuscripts}




\title{
FASTING HYPERGLYCAEMIA AND IN-HOSPITAL MORTALITY IN ELDERLY POPULATION
}

\author{
(Revised version, R1)
}

\begin{abstract}
Pedro Iglesias ${ }^{1}$, Antonio Polini ${ }^{2}$, Angélica Muñoz ${ }^{3}$, Angela Dardano ${ }^{2}$, Florentino Prado ${ }^{3}$, Maido Castiglioni ${ }^{2}$, María Teresa Guerrero ${ }^{3}$, Sara Tognini ${ }^{4}$, Maria Cruz Macías ${ }^{3}$, Juan J. Díez ${ }^{1}$, and Fabio Monzani².
\end{abstract}

${ }^{1}$ Department of Endocrinology, Hospital Ramón y Cajal, Madrid, Spain. ${ }^{2}$ Department of Internal Medicine, University of Pisa, Italy. ${ }^{3}$ Department of Geriatrics, Hospital General, Segovia, Spain. ${ }^{4}$ Department of Internal Medicine, Cisanello Hospital, Pisa, Italy.

Abbreviated version of the title: Hyperglycaemia and in-hospital mortality Key-words: fasting, hyperglycaemia, in-hospital, mortality, elderly

\section{Correspondence:}

Pedro Iglesias, MD

Department of Endocrinology Hospital Ramón y Cajal

Ctra. de Colmenar km 9.100 28034 Madrid SPAIN

e-mail:piglo65@gmail.com 
BACKGROUND Admission hyperglycaemia has shown to be a marker of poor clinical outcome. The prevalence of admission hyperglycaemia and its relationship with in-hospital mortality in elderly population has not been clearly defined. We assessed the prevalence and prognostic significance of admission fasting hyperglycaemia in aged patients.

METHODS 808 elderly patients were studied. Patients were classified into group I (serum glucose $<126 \mathrm{mg} / \mathrm{dl})$, II (126-180 mg/dl) and III (>180 mg/dl). Groups II and III were considered as newly recognized fasting hyperglycaemia (NRFH) in non diabetic patients.

RESULTS NRFH was present in $18.6 \%$. After excluding diabetic patients ( $n=206,25.5 \%$ ), the distribution of patients ( $n=602,74.5 \%)$ was as follows: group I $(n=452,55.9 \%)$, group II $(n=122$, $15.1 \%)$ and group III ( $n=28,3.5 \%)$. In the whole cohort median fasting glucose was lower in patients who survived [105 mg/dl (88-135)] than in those who died [127 mg/dl (93-159), $\mathrm{P}<0.001]$. This significant difference was maintained only when non-diabetic patients were considered [100 mg/dl (87-122) vs $118 \mathrm{mg} / \mathrm{dl}$ (92-149), $\mathrm{P}<0.001]$. In-hospital mortality rate in groups I, II, and III was $8.5 \%, 14.1 \%$, and $22.9 \%$, respectively $(\mathrm{P}<0.001)$. Mortality rate was $8.4 \%, 18.0 \%$, and $32.1 \%(\mathrm{P}<0.001)$ in groups $\mathrm{I}$, II and III, respectively in non-diabetic population. Both low albumin and high glucose serum concentrations were the only independent risk factors for in-hospital all-cause mortality in non-diabetic patients.

CONCLUSIONS In non-diabetic elderly patients admitted for acute disease, serum glucose concentration is an important, simple and independent predictor of hospital mortality. 


\section{What's known}

- In adult nondiabetic inpatients elevated admission blood glucose levels have increased in-hospital mortality rate in both non-ICU and ICU settings.

- Elderly nondiabetic inpatients with admision hyperglycaemia have also shown increased in-hospital mortality rate in both sub-intensive and intensive care units.

\section{What's new}

- Elderly nondiabetic inpatients with in-hospital hyperglycaemia show increased inhospital mortality rate in both geriatric and internal medicine units admitted for acute disease regardless of aetiology.

\section{Introduction}

Admission or in-hospital hyperglycaemia has shown to be a common finding in adult patients with and without a history of diabetes (DM) and has been identified as an important marker of poor clinical outcome and mortality (1-4). In diabetic patients with myocardial infarction (MI), stress hyperglycaemia is associated with an increased risk of in-hospital mortality (1). In non-diabetics, acute hyperglycaemia predicts increased risk of in-hospital mortality after ischemic stroke and increases risk of both poor functional recovery in stroke survivors and congestive heart failure or cardiogenic shock in Ml survivors (1,2). Adult patients without previous history of DM and elevated admission blood glucose levels had higher admission rate to an intensive care unit (ICU) than patients with a prior diagnosis of DM and normoglycaemic patients (3).

In-hospital mortality rate has been reported to be significantly increased in adult patients with in-hospital hyperglycaemia. Mortality rate in patients with newly recognized fasting hyperglycaemia (NRFH) was 5 and 9 times higher than in diabetic and in normoglycaemic patients, respectively (3). The high mortality rate observed in these patients has been reported in both non-ICU and ICU patients (3).

There has also been reported a strong relationship between NRFH and mortality in elderly patients hospitalized for heart failure (5). This biochemical condition was also independently associated with in-hospital and 45-day mortality in acutely ill elderly patients without a history of DM admitted to a sub-intensive care unit (sub-ICU) for elderly patients (4). To the best of our knowledge, the prevalence of NRFH and its relationship with in-hospital mortality in elderly population admitted to a Geriatric or Internal Medicine Departments for acute illness has not been clearly defined. The aim of this study was (1) to assess the prevalence of NRFH at admission in aged hospitalized patients for any acute illness and (2) to study the relationship between fasting blood glucose levels and in-hospital mortality in these patients. 


\section{Patients and methods}

This is a prospective observational study performed in a large population of patients older than 60 years hospitalized for acute illness. Patients were recruited from the Geriatric Department, Hospital General (Segovia, Spain) and from the Department of Internal Medicine, Hospital Cisanello (Pisa, Italy). All admitted patients were included in the study regardless of the cause of hospitalization. Admission criteria were considered when the patients showed acute illness or exacerbation of a chronic disease not requiring sub-ICU or ICU care. The Spanish cohort came from all patients consecutively admitted to the geriatric unit during 2005. The Italian cohort came from all patients over 60 years consecutively admitted to the Internal Medicine Department from January to July 2008. A detailed clinical history, review of the previous case record, and physical examination were performed in every patient. In geriatric Spanish cohort functional status at entry was evaluated by using the modified version of Barthel index (6). This index evaluates 10 basic activities of everyday life with a score that ranges from 0 (maximal dependence) to 100 (maximal independence). Blood samples were drawn for the measurement of routine biochemical parameters at 8.00 after an overnight fast of the following day after admission. Analytical parameters were measured by using an automatic biochemical auto-analyzer (Hitachi 917 Analyzer, Roche Diagnostics, Mannheim, Germany in Segovia and Hitachi Cobas 6000, C501 Analyzer, Roche Diagnostics, IN, USA, in Pisa). The following demographic, clinical, and laboratory data were recorded: personal history of smoking, hypertension, DM, dyslipidemia, cardiopathy and tumor disease, age, gender, weight, body mass index (BMI), systolic and diastolic blood pressure, and serum concentrations of glucose, creatinine, total cholesterol, high-density lipoprotein (HDL) cholesterol, low-density lipoprotein (LDL) cholesterol, triglycerides and albumin. Hospital stay, in-hospital survival time and number of deaths during hospitalization were registered. Serum glucose concentrations were arbitrarily categorized for study purposes into group I (<126 mg/dl), II (126-180 mg/dl) and III (>180 mg/dl) before completion of the study. Groups II and III were considered as NRFH only in those patients without a history of DM. The study was approved by local ethical committee of each hospital and informed consent was given by subjects prior to participation in the study.

\section{Statistical analysis}

For quantitative variables, results are expressed as mean \pm SD for normally distributed data, and as median (interquartilic range) for nonparametric data. Adjustment to normal distribution was tested by the Kolmogorov test. Categorical variables are described as percentages. For comparisons of means between two groups of subjects the Student t-test was used for normally distributed data, and the Mann-Whitney test was employed for nonparametric data. For ratio comparisons the $\chi^{2}$ test was used. Survival time was estimated by the KaplanMeier method, with the log-rank test used to compare arms. Univariate and stepwise 
multivariate Cox regression models were used to assess the independent effects of several quantitative and qualitative variables on the risk of death. Hazard ratios (HR) and their $95 \%$ confidence intervals for all-cause mortality were estimated. Differences were considered significant when $\mathrm{P}<0.05$.

\section{Results}

Clinical features and analytical data

A group of 808 elderly patients [median age (interquartilic range) 84 years (78-89), 458 women (56.7\%) and 350 men (43.3\%)] admitted to hospital [Segovia, Spain ( $n=447,55.3 \%)$ and Pisa, Italy $(n=361,44.7 \%)]$ with acute illness were studied. The Spanish cohort was older, with higher proportion of women and hypertensive patients, lower systolic and diastolic blood pressures, higher serum glucose and creatinine and lower total cholesterol concentrations than the Italian cohort. The main causes for admission were congestive heart failure (152 patients, $18.8 \%$ ), respiratory tract infection (101 patients, 12.5\%), acute cerebrovascular disease (95 patients, $11.8 \%$ ), exacerbation of chronic obstructive pulmonary disease (69 patients, $8.5 \%$ ), cancer (64 patients, 7.9\%), ischaemic cardiopathy (34 patients, 4.2\%), acute digestive haemorrhage (34 patients, $4.2 \%$ ), sepsis (15 patients, 1.9\%) and other (244 patients, $30.2 \%$ ). Significant differences $(P<0.001)$ were found in the distribution of main causes for admission between the two cohorts. There were more patients with initial diagnosis of exacerbation of chronic obstructive pulmonary disease $(12.2 \%$ vs $5.6 \%)$ and cancer $(12.1 \%$ vs $3.8 \%)$ in the Italian cohort. On the contrary, Spanish cohort showed more patients with acute cerebrovascular disease (14.9\% vs $7.7 \%$ ), acute digestive haemorrhage (6.5\% vs $1.4 \%)$ and sepsis $(3.0 \%$ vs $0.5 \%)$ than Italian cohort. Clinical and analytical data of the studied patients are summarized in Table 1.

\section{Prevalence of newly recognized fasting hyperglycaemia}

After excluding diabetic patients $(n=206,25.5 \%)$, the distribution of the remaining patients ( $n=602,74.5 \%)$ according to glucose values was $452(55.9 \%)$ in group I, $122(15.1 \%)$ in group II and 28 patients (3.5\%) in group III. The total prevalence of NRFH was $18.6 \%$. Median (interquartilic range) glucose level in each group was $93 \mathrm{mg} / \mathrm{dl}$ (84-105), $142 \mathrm{mg} / \mathrm{dl}$ $(132.7-154.2)$ and $210 \mathrm{mg} / \mathrm{dl}(191.5-273.2)(\mathrm{P}<0.001)$. When comparing NRFH with group I patients, no difference in sex distribution, main diagnosis for admission, history of dyslipidemia, heart disease, arrhythmias, cardiovascular disease, and smoking habitus was observed. In relation to biochemical parameters only serum glucose [147 mg/dl (134.7-171) vs $93 \mathrm{mg} / \mathrm{dl}$ (84105), $P<0.001]$ and creatinine [1.2 mg/dl (0.9-1.6) vs $1.1 \mathrm{mg} / \mathrm{dl}(0.8-1.3), P=0.001]$ levels were statistically significant. 


\section{Fasting hyperglycaemia and hospital mortality}

In the whole group, the median fasting glucose was lower in patients who survived [105 $\mathrm{mg} / \mathrm{dl}$ (88-135)] than in those who died [127 mg/dl (93-159), $\mathrm{P}<0.001]$. This significant difference was maintained only when non-diabetic patients were considered [100 mg/dl (87-122) vs 118 $\mathrm{mg} / \mathrm{dl}$ (92-149), $\mathrm{P}<0.001]$. When analyzing the entire cohort of patients, the hospital mortality rates in patients from groups I, II, and III were $8.5 \%, 14.1 \%$, and $22.9 \%$, respectively $(\mathrm{P}<0.001)$. In subjects without DM, mortality rates were $8.4 \%, 18.05$ and $31.2 \%$ in groups I, II and III, respectively $(\mathrm{P}<0.001)$. In diabetic patients, mortality rates were $8.6 \%, 7.2$ and $18.2 \%$ in groups I, II and III, respectively (P=NS) (figure 1 ) .

\section{Hospital survival time and fasting hyperglycaemia}

During hospitalization (mean hospital stay $10.5 \pm 7.5$ days), 91 (11.3\%) patients died (mean hospitalization time until death $11.3 \pm 10.9$ days). The Italian cohort presented a lower mortality rate $(7.7 \%$ vs $14.1 \%, P=0.005)$ and mean hospital stay $(8.9 \pm 5.1$ vs $12.0 \pm 8.8$ days, $\mathrm{P}<0.001$ ) than the Spanish cohort, but hospitalization time until death was similar in both groups. Kaplan-Meier analysis showed a mean hospital survival time for all-cause mortality of 38.5 (95\% C.I., 33.1-43.9), 41.3 (95\% C.I., 35.4-47.2) and 36.4 (95\% C.I., 30.2-42.7) days in groups I, II and III, respectively (log-rank $\chi^{2} 7.18, \mathrm{P}<0.05$ ). When considering only non-diabetic patients mean hospital survival time was 40.5 (95\% C.I., 34.0-47.0), 40.3 (95\% C.I., 33.4-47.2) and 28.5 (95\% C.I., 5.1-18.6) days in groups I, II and III, respectively (log-rank $\chi^{2} 12.5, \mathrm{P}=0.002$ ) (figure 2). No significant difference in mean hospital survival time between I, II and III groups was observed when diabetic patients were evaluated. In the whole cohort, unadjusted Cox regression model showed that death risk was directly related to age (HR 1.04; 95\% C.I. 1.011.07, $p<0.01$ ) while inversely to serum LDL-cholesterol (HR 0.99; 95\% C.I. 0.98-0.99, $p<0.05$ ), HDL-cholesterol (HR 0.97; 95\% C.I. 0.96-0.99, p<0.01) and albumin (HR 0.46; 95\% C.I. 0.310.66. $p<0.001$ ) concentrations. However, in the multivariate (adjusted) analysis serum albumin value remained the only significant factor related to mortality (HR $0.35 ; 95 \%$ C.I. $0.21-0.59$. $\mathrm{p}<0.001$ ) (Table 2). Among non-diabetic patients, beside the previous described parameters also serum glucose levels positively correlated with mortality rate (HR 1.006; 95\% C.I. 1.0021.011. $\mathrm{p}<0.01)$. Interestingly, in the multivariate (adjusted) analysis both reduced albumin (HR 0.33; 95\% C.I. 0.18-0.59. p<0.001) and elevated glucose (HR 1.006; 95\% C.I. 1.001-1.012. $p<0.05$ ) values emerged as significant risk factors of increased mortality rate (Table 2). Lastly, we did not find any risk factor associated with in-hospital mortality among diabetic patients.

\section{Discussion}

This is the first multicentre, prospective study assessing fasting serum glucose values in relation to in-hospital mortality in a large cohort of elderly patients admitted in different medical 
departments. Our results show that the prevalence of NRFH at admission in aged hospitalized patients for any acute illness is relatively high, about $19 \%$. Fasting glucose value emerged a significant risk factor for death during hospitalization, especially in non-diabetic patients.

Fasting hyperglycaemia in patients admitted with myocardial infarction with and without DM (1) and after ischemic stroke in non-diabetic patients (2) is associated with an increased risk of in-hospital mortality. The association between hyperglycaemia and in-hospital mortality is also well known among patients without diabetic history in the cardiac, cardiothoracic, and neurosurgical ICUs $(7,8)$. In a retrospective study performed in 1886 adult patients admitted to a general hospital, NRFH had a significantly higher mortality rate and a lower functional outcome than either patients with a known history of DM or normoglycemia (3). More recently, a retrospective study a relationship between NRFH and higher mortality rate in critically acute ill elderly patients admitted to a sub-ICU has been reported (4). To the best of our knowledge, the current is the first prospective survey that provides a clear association between elevated fasting glycaemia and higher in-hospital mortality in a large population of non-diabetic older patients, hospitalized for acute illness in non sub-ICU or ICU (i.e. in geriatric and internal medicine units).

NRFH is a common finding ( 12\%) in hospitalized patients for acute ill disease (3). Prevalence of NRFH is even higher (38\%) in elderly patients without DM admitted to a Sub-ICU (4). In our non-diabetic population this prevalence was $25 \%$, most of them belonged to group II. One interesting finding is the relationship found between basal hyperglycaemia and hospital mortality in acutely ill patients without history of DM. In adult patients, newly discovered hyperglycaemia was associated with elevated in-hospital mortality rate (16\%), about 5 and 9 times higher than in the diabetic population and normoglucaemic subjects, respectively (3). In elderly patients without DM admitted to a Sub-ICU the presence of NRFN was also associated with high in-hospital mortality rate (23\%), about 1.8 times higher than in the diabetic population (4). Our findings agree with these results showing a significant lower median fasting glucose in patients who survived than in those who died with a mortality rate about 2 times higher in NRFH subjects than in diabetic patients. We also observed that fasting hyperglycaemia was associated to in-hospital survival time in non-diabetics; the higher fasting glucose values the lower mean hospital survival time. On the other hand, the difference in mortality and hospital staty between Spanish and Italian cohorts was esentially due to the different age and causes of hospitalization in both populations.

Stress-induced hyperglycaemia $(\mathrm{SH})$ is a transient elevation of the blood glucose due to the stress of illness and must be distinguished from different types of DM. Serum glucose level is typically in the range of $140-300 \mathrm{mg} / \mathrm{dl}$, but occasionally can be even higher than $500 \mathrm{mg} / \mathrm{dl}$, especially if it is amplified by drugs or intravenous glucose (9). $\mathrm{SH}$ is a metabolic disorder potentially toxic in critically ill patients since it can induce a proinflammatory state. Hyperglycaemia promotes an excessive cellular glucose overload and an increased cellular 
oxidative stress as a consequence of free radicals generation induced by excessive glycolysis and oxidative phosphorylation (10-12). The combination of hyperglycaemia and relative hyperinsulinaemia has been proposed as a plausible explanation for the poor hospital outcomes seen in observational studies (9).

Because of the relationship between hyperglycaemia and hospital mortality several studies, mainly conducted in ICUs, have evaluated the possible therapeutic beneficial effect on hospital mortality of controlling SH with insulin (13-15). Our study showed a high mortality and short hospital survival in non-diabetic elderly patients with baseline hyperglycaemia greater than $180 \mathrm{mg} / \mathrm{dl}$. These data suggest that a blood glucose target of $180 \mathrm{mg} / \mathrm{dl}$ or less might also be an appropriate blood glucose target in non-diabetic elderly population.

There is a well-known association between serum albumin concentration and hospital mortality in in critically ill patients (16). This finding was also documented in our study population, being the most important mortality risk marker, even higher than NRFH.

In conclusion, in non-diabetic elderly patients admitted for acute disease, serum glucose concentration is an important, simple and independent predictor of mortality and is associated to mean in-hospital survival time. These findings should help us to identify those patients at high vital risk during hospitalization in order to intensify therapy for improving prognosis. 


\section{References}

1. Capes SE, Hunt D, Malmberg K, Gerstein HC. Stress hyperglycaemia and increased risk of death after myocardial infarction in patients with and without diabetes: A systematic overview. Lancet. $2000 ; 355: 773-8$.

2. Capes SE, Hunt D, Malmberg K, Pathak P, Gerstein HC. Stress hyperglycemia and prognosis of stroke in nondiabetic and diabetic patients: A systematic overview. Stroke. 2001 ; $32: 2426-32$.

3. Umpierrez GE, Isaacs SD, Bazargan N, You X, Thaler LM, Kitabchi AE. Hyperglycemia: An independent marker of in-hospital mortality in patients with undiagnosed diabetes. $J$ Clin Endocrinol Metab. $2002 ; 87$ : 978-82.

4. Sleiman I, Morandi A, Sabatini T, Ranhoff A, Ricci A, Rozzini R, Trabucchi M. Hyperglycemia as a predictor of in-hospital mortality in elderly patients without diabetes mellitus admitted to a sub-intensive care unit. J Am Geriatr Soc. 2008 ; 56 : 1106-10 .

5. Sleiman I, Rozzini R, Giordano A, Trabucchi M. Short-term survival in elderly patients hospitalized for heart failure: The role of diabetes mellitus and newly recognized hyperglycemia. J Am Geriatr Soc. 2009 ; 57 : 1313-6.

6. Shah S, Vanclay F, Cooper B. Improving the sensitivity of the barthel index for stroke rehabilitation. J Clin Epidemiol. $1989 ; 42$ : 703-9.

7. Whitcomb BW, Pradhan EK, Pittas AG, Roghmann MC, Perencevich EN. Impact of admission hyperglycemia on hospital mortality in various intensive care unit populations. Crit Care Med. 2005 ; 33 : 2772-7.

8. Krinsley JS. Association between hyperglycemia and increased hospital mortality in a heterogeneous population of critically ill patients. Mayo Clin Proc. 2003 ; 78 : 1471-8.

9. Clement S, Braithwaite SS, Magee MF, Ahmann A, Smith EP, Schafer RG, Hirsch IB, American Diabetes Association Diabetes in Hospitals Writing Committee. Management of diabetes and hyperglycemia in hospitals. Diabetes Care. $2004 ; 27$ : 553-91.

10. Muniandy S, Qvist R, Yan GO, Bee CJ, Chu YK, Rayappan AV. The oxidative stress of hyperglycemia and the inflammatory process in endothelial cells. J Med Invest. 2009 ; 56 : 610 .

11. Weekers F, Giulietti AP, Michalaki M, Coopmans W, Van Herck E, Mathieu C, Van den Berghe G. Metabolic, endocrine, and immune effects of stress hyperglycemia in a rabbit model of prolonged critical illness. Endocrinology. $2003 ; 144$ : 5329-38 .

12. Vanhorebeek I, Ellger B, De Vos R, Boussemaere M, Debaveye Y, Perre SV, Rabbani N, Thornalley PJ, Van den Berghe G. Tissue-specific glucose toxicity induces mitochondrial damage in a burn injury model of critical illness. Crit Care Med. 2009 ; 37 : 1355-64 .

13. van den Berghe G, Wouters P, Weekers F, Verwaest C, Bruyninckx F, Schetz M, Vlasselaers D, Ferdinande P, Lauwers $P$, Bouillon R. Intensive insulin therapy in the critically ill patients. N Engl J Med. 2001 ; 345 : 1359-67.

14. Van den Berghe G, Wilmer A, Hermans G, Meersseman W, Wouters PJ, Milants I, Van Wijngaerden $\mathrm{E}$, Bobbaers $\mathrm{H}$, Bouillon R. Intensive insulin therapy in the medical ICU. $N$ Engl $J$ Med. 2006 ; 354 : 449-61.

15. Wiener RS, Wiener DC, Larson RJ. Benefits and risks of tight glucose control in critically ill adults: A meta-analysis. JAMA. 2008 ; 300 : 933-44 .

16. Yap FH, Joynt GM, Buckley TA, Wong EL. Association of serum albumin concentration and mortality risk in critically ill patients. Anaesth Intensive Care. 2002 ; $30: 202-7$. 
Tables

Table 1. Clinical and analytical data of the studied patients.

\begin{tabular}{|c|c|c|c|}
\hline & Spanish cohort & Italian cohort & total \\
\hline Number of patients (\%) & 447 (55.3) & $361(44.7)$ & 808 \\
\hline Sex, M/F (\%) & $170(38) / 277(62)^{* *}$ & $180(49.9) / 181(50.1)$ & $350(43.3) / 458(56.7)$ \\
\hline Age (years) & $86(81-90)^{\star *}$ & $80(73-85)$ & $84(78-89)$ \\
\hline Smoking & $10(2.2)^{\star *}$ & $51(14.1)$ & $61(7.5)$ \\
\hline Diabetes & $118(26.4)$ & $88(24.4)$ & $206(25.5)$ \\
\hline Hypertension & $248(55.5)^{*}$ & $161(44.6)$ & $409(50.6)$ \\
\hline Dyslipidemia & $71(15.9)$ & $49(13.6)$ & $120(14.9)$ \\
\hline Cardiopathy & $148(33.1)^{\star *}$ & $187(51.8)$ & $335(41.5)$ \\
\hline Malignant tumors & $59(13.2)^{\star *}$ & $136(37.7)$ & $195(24.1)$ \\
\hline $\mathrm{BMI}\left(\mathrm{kg} / \mathrm{m}^{2}\right)$ & $27.2 \pm 5.2$ & $26.6 \pm 5.1$ & $27.1 \pm 4.9$ \\
\hline $\mathrm{SBP}(\mathrm{mmHg})$ & $130(110-150)^{\star \star}$ & $140(120-160)$ & $130(120-150)$ \\
\hline $\mathrm{DBP}(\mathrm{mmHg})$ & $70(60-80)^{\star *}$ & $80(70-85)$ & $75(70-80)$ \\
\hline Glucose (mg/dl) & $117(94-150)^{* *}$ & $99(82-123)$ & $106(89-138)$ \\
\hline Creatinine $(\mathrm{mg} / \mathrm{dl})$ & $1.2(0.9-1.5)^{\star \star}$ & $0.9(0.7-1.3)$ & $1.1(0.8-1.5)$ \\
\hline Cholesterol (mg/dl) & $152.0 \pm 39.8^{*}$ & $160.5 \pm 47.7$ & $156.0 \pm 43.9$ \\
\hline HDL cholesterol (mg/dl) & $42(34-55)$ & $42(31-56)$ & $42(33-55)$ \\
\hline LDL cholesterol (mg/dl) & $88(64-108)$ & $93(63-119)$ & $91(63-113)$ \\
\hline Triglycerides (mg/dl) & $89(69-117)$ & $92(68-128)$ & $90(68-122)$ \\
\hline Albumin (g/dl) & $3.3(2.9-3.6)$ & $3.3(2.9-3.7)$ & $3.3(2.9-3.6)$ \\
\hline
\end{tabular}

Abbreviations: M, male; F, female; BMI, body mass index; SBP, systolic blood pressure; DBP, diastolic blood pressure; HDL, high-density lipoprotein; LDL, low-density lipoprotein. Note: Figures indicate the number of patients (\%) and/or the mean \pm SD for normal variables and median (interquartilic range) for nonparametric data.

${ }^{*} \mathrm{p}<0.01 ;{ }^{* *} \mathrm{p}<0.001$; Spanish vs Italian cohort 
Table 2. A. Non-adjusted and adjusted hazard ratios (with 95\% C.I.) for the development of in-hospital mortality (Cox models) in several clinical and analytical variables in the entire cohort of studied patients $(n=808)$ and in 602 non-diabetic patients

\begin{tabular}{|c|c|c|c|c|}
\hline & \multicolumn{2}{|c|}{$\begin{array}{c}\text { All patients } \\
n=808\end{array}$} & \multicolumn{2}{|c|}{$\begin{array}{c}\text { Non-diabetic patients } \\
n=602\end{array}$} \\
\hline & $\begin{array}{c}\text { Univariate (unadjusted) } \\
\text { analysis }\end{array}$ & $\begin{array}{c}\text { Multivariate (adjusted) } \\
\text { analysis }\end{array}$ & $\begin{array}{c}\text { Univariate (unadjusted) } \\
\text { analysis }\end{array}$ & $\begin{array}{c}\text { Multivariate (adjusted) } \\
\text { analysis }\end{array}$ \\
\hline Variable & Hazard ratio (95\% C.I.) & Hazard ratio (95\% C.I.) & Hazard ratio (95\% C.I.) & Hazard ratio (95\% C.I.) \\
\hline Sex (male) & $1.09(0.72-1.66)$ & & $0.94(0.58-1.52)$ & \\
\hline Age & $1.04(1.01-1.07)^{* *}$ & & $1.04(1.01-1.08)^{* *}$ & \\
\hline Hospital of origin (Segovia) & $1.18(0.74-1.86)$ & & $1.34(0.79-2.26)$ & \\
\hline Barthel index at entry & $0.99(0.98-1.00)$ & & $0.98(0.98-0.99)^{* *}$ & \\
\hline Diabetes mellitus & $1.26(0.77-2.04)$ & & & \\
\hline Hypertension & $1.18(0.78-1.79)$ & & $1.27(0.77-2.07)$ & \\
\hline Dyslipidemia & $1.25(0.68-2.31)$ & & $1.41(0.61-3.27)$ & \\
\hline Cardiopathy & $0.93(0.62-1.42)$ & & $1.00(0.61-1.64)$ & \\
\hline Glucose & $1.00(0.99-1.00)$ & & $1.006(1.002-1.011)^{\star *}$ & $1.006(1.001-1.012)^{*}$ \\
\hline Creatinine & $1.18(0.98-1.41)$ & & $1.18(0.98-1.43)$ & \\
\hline Cholesterol & $0.99(0.99-1.00)$ & & $0.99(0.99-1.00)$ & \\
\hline LDL cholesterol & $0.99(0.98-0.99)^{*}$ & & $0.99(0.98-1.00)$ & \\
\hline HDL cholesterol & $0.97(0.96-0.99)^{* *}$ & & $0.97(0.95-0.99)^{*}$ & \\
\hline Triglycerides & $1.00(0.99-1.00)$ & & $1.00(0.99-1.00)$ & \\
\hline Albumin & $0.46(0.31-0.66)^{\star \star \star}$ & $0.35(0.21-0.59)^{\star \star *}$ & $0.46(0.30-0.70)^{\star \star *}$ & $0.33(0.18-0.59)^{\star \star \star}$ \\
\hline
\end{tabular}

${ }^{*} \mathrm{P}<0.05 ;{ }^{* *} \mathrm{P}<0.01$; ${ }^{* * *} \mathrm{P}<0.001$

$\mathrm{Cl}$, Confidence intervals 


\section{Legends for figures}

Figure 1. In-hospital mortality rate in elderly patients admitted for acute illness according to fasting serum glucose concentrations after admission.

Figure 2. Kaplan-Meier survival analysis for all-cause mortality after admission in 602 nondiabetic elderly patients admitted for acute illness stratified according to groups of fasting serum glucose concentrations. 
Figure 1

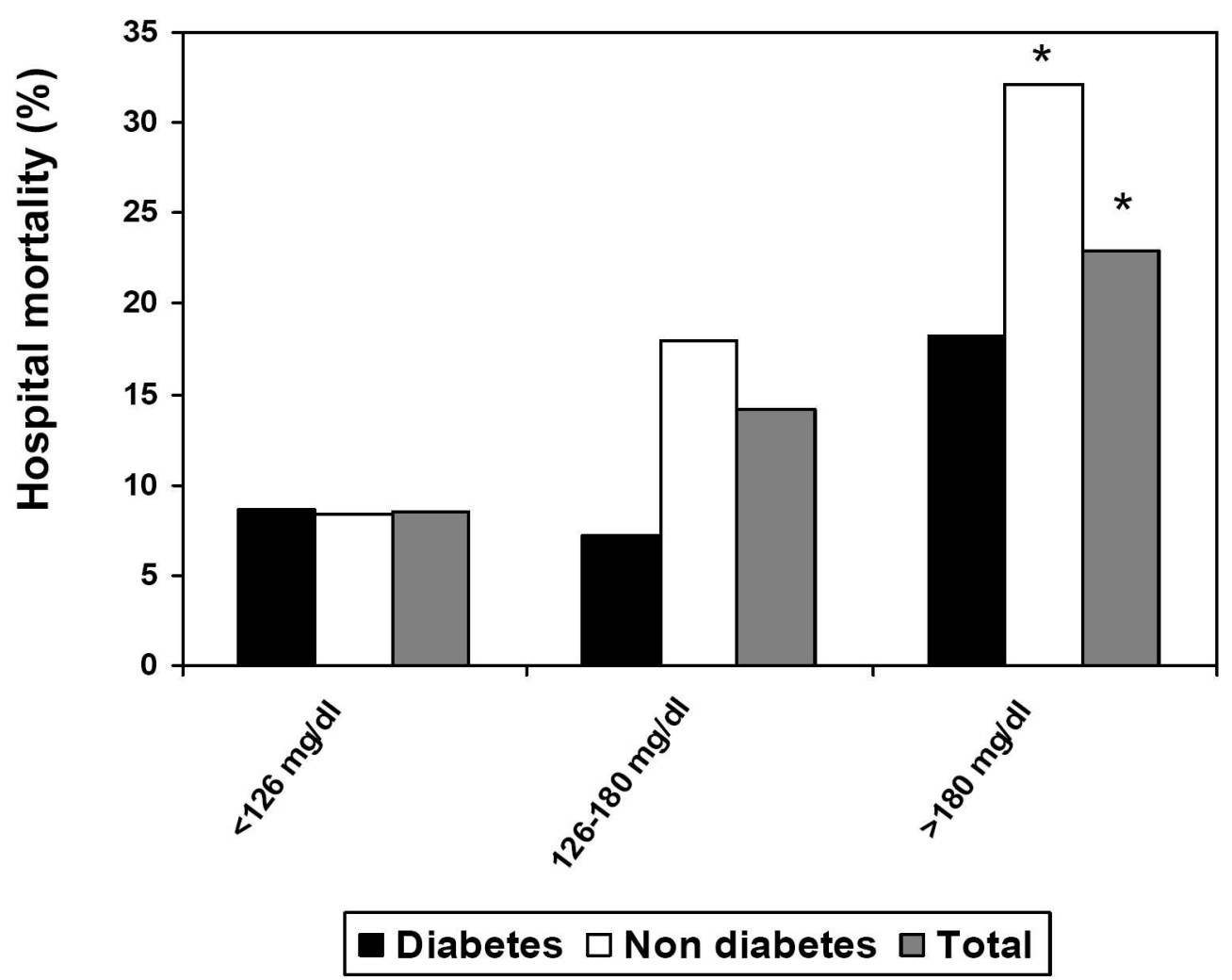

${ }^{*} \mathrm{P}<0.001$ for the difference in mortality rate in non-diabetics and in total $(\chi 2)$ 
Figure 2

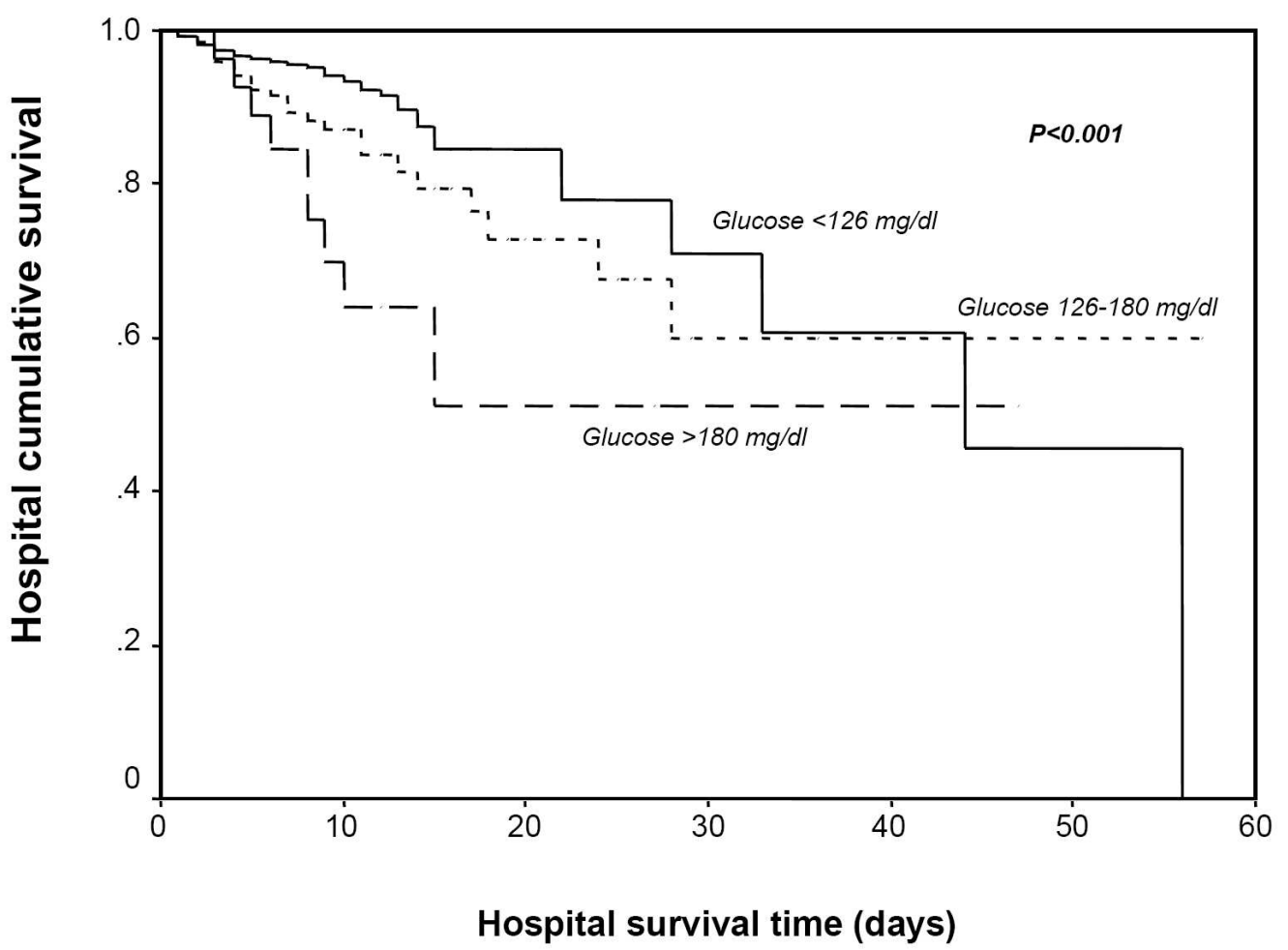

